\title{
Criterios organicistas en el diseño del mobiliario urbano del Jardín Botánico El Cerro
}

Adelaida Barba Gallego ${ }^{1}$

$M^{a}$ Carmen Ladrón de Guevara Muñoz ${ }^{2}$

Elidia Beatriz Blázquez Parra ${ }^{3}$

Francisca J. Castillo Rueda 4

Escuela de Ingenierías Industriales. Universidad de Málaga

RECIBIDO: 30.01.2017 / ACEPTADO: 15.03.2017

\section{Resumen}

El Jardín Botánico El Cerro, situado en el municipio del Rincón de la Victoria de Málaga, tiene previsto su próxima apertura en breve. A la hora de diseñar un jardín no sólo son importantes las especies que va a acoger, sino también son imprescindibles otros elementos que contribuyen a la satisfacción de las necesidades de los usuarios. Este es el caso del mobiliario, que está íntimamente relacionado con las visitas y el tránsito que va a soportar, haciendo más agradable y confortable el entorno. El papel del diseñador industrial es fundamental en estas tareas relacionadas con el diseño del mobiliario. Es por ello, que en este artículo se muestra y analiza un caso práctico real de Diseño Industrial. Para tal fin, se desarrollan los diseños de bancos, papeleras y fuentes de agua potable, como elementos primordiales para cubrir las necesidades del público visitante del Jardín Botánico basados en las especies del mismo.

Palabras clave: diseño de mobiliario, organicista, jardín botánico.

\section{Organic criteria in the design of urban furniture EI Cerro Botanic Garden}

\footnotetext{
Abstract

El Cerro Botanic Garden located in the municipality of Rincón de la Victoria (Málaga) is expected to open shortly. Upon designing a garden, not only are the species to include important but, the urban furniture as well, since it is closely

1 Ingeniera Técnica en Diseño Industrial por la Escuela Politécnica Superior de Málaga

2 Arquitecta e Ingeniera Técnica Industrial en Mecánica por la Universidad de Málaga, B.Sc. en Ingeniería Mecánica por la Universidad de Skövde y Máster en Representación y Diseño en Ingeniería y Arquitectura.

3 Ingeniera en Geodesia y Cartografía por la Universidad de Jaén, Licenciada en Bellas Artes por la Universidad de Málaga, Doctora en Ingeniería por la Universidad de Jaén. Profesora de la Escuela de Ingenierías Industriales de la Universidad de Málaga.

${ }^{4}$ Ingeniera Técnica en Electrónica por la Escuela Universitaria Politécnica de Málaga, Máster en Fotovoltaica por la UNIA, Profesora de la Escuela de Ingenierías Industriales de la Universidad de Málaga.
} 
related to the visits and the transit that the garden will receive, making the surroundings more pleasant and comforting. The role of the industrial designer becomes essential at developing the different tasks involved in the process of urban furniture design. Thereby, this paper illustrates and analyzes a real-life case of Industrial Design. To this extent, benches, paper bins and potable water fountains are developed as key elements to satisfy the needs of the Botanic Garden visitors.

Keywords: urban furniture design, organicist, botanic garden.

\section{Introducción}

La presencia de jardines en la planificación urbanística de las ciudades es manifiesta y fundamental. Existen exigencias legales, tanto a nivel nacional como a nivel regional, sobre la calidad urbana en la que los espacios libres públicos son un hito fundamental. Estas leyes pretenden asegurar la creación de parques y jardines con unas condiciones de seguridad y bienestar suficientes, como indica Emilio Larrodera (1982). Además cabe destacar que en general, las zonas verdes de dimensiones generosas le confieren a la ciudad un aspecto saludable y un reconocimiento exterior importante. Estos espacios representan, por una parte, un lugar de ocio y deleite para los usuarios, compuesto de distintas especies vegetales y otros elementos tales como lagos, fuentes y esculturas. Y por otra parte, contribuyen a la reducción de la huella del carbono producida por la ciudad.

A lo largo de la historia, son numerosos los ejemplos de extraordinarios jardines. A nivel internacional encontramos, por ejemplo, el jardín de Keikenhof en Holanda, con unas 32 hectáreas y con una impresionante colección de especies vegetales, invernaderos, lagos, fuentes o grandes paseos; también, el Jardín tropical de la isla de Mainau en Alemania, cuyas flores y arbustos representan varios objetos o animales; o en México el Jardín de las Pozas de Xilitla, conjunto artístico, arquitectónico y escultórico surrealista realizado por Edwar James, o los Jardines de Suzhou en China, considerados como Patrimonio de la Humanidad. En el panorama nacional destacan algunos como los jardines del Generalife en la Alhambra, de origen oriental en el que el agua es un elemento fundamental. Los Jardines del Real Alcázar de Sevilla y los Jardines de la La Granja de San Ildefonso de Segovia con una extensión de seis kilómetros, que constituyen un ejemplo de diseño de jardines de la Europa del siglo XVIII.

La búsqueda del confort de los ciudadanos fuera de sus hogares ha contribuido en el desarrollo de zonas verdes en las ciudades que cumplan con la satisfacción de las necesidades físicas y psicológicas de los usuarios. Así, estudios como el realizado por Polat et al (2015) estudian las relaciones entre la calidad visual de las áreas urbanas de recreo y los elementos del paisaje estructurales y de vegetación teniendo en cuenta los visitantes.

En este artículo se muestra un caso práctico real de diseño industrial vinculado al diseño de los elementos estructurales del Jardín Botánico "El Cerro". Se desarrollan los diseños de bancos, papeleras y fuentes de agua potable, como elementos primordiales para cubrir las necesidades del público visitante del jardín basados en las especies del mismo. 


\section{El Jardín Botánico “El Cerro”}

El Jardín Botánico "El Cerro" se sitúa en el término municipal del Rincón de la Victoria, perteneciente a la provincia de Málaga. La configuración de zona verde se podría describir como de aspecto tropical, muy frondosa y que contrasta con el secarral de su entorno, provocando que el visitante, al introducirse en él, experimente la sensación de adentrarse en un auténtico oasis tropical tal y como se refleja en la figura 1.
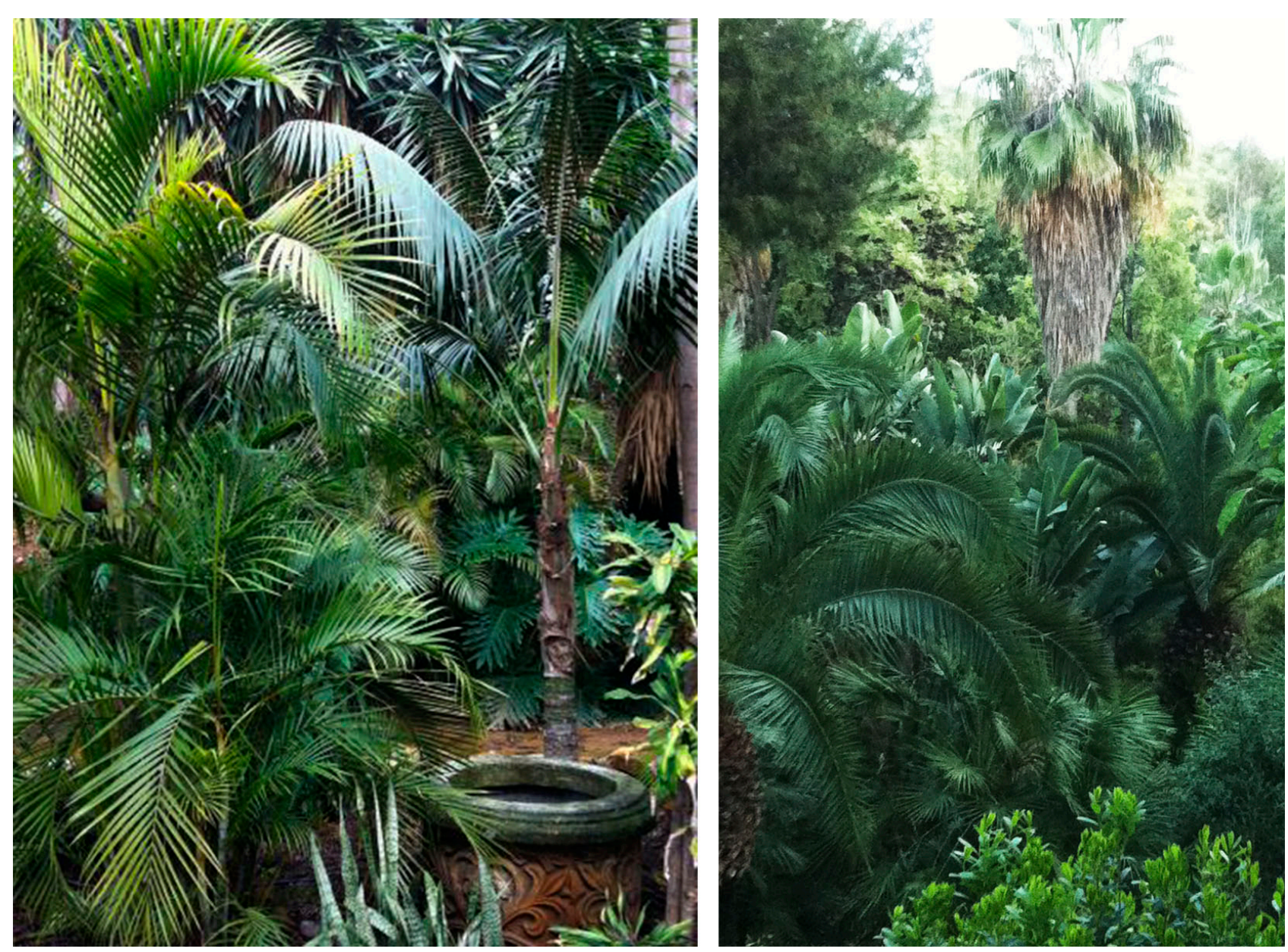

Fig. 1. Vistas del Jardín Botánico "El Cerro".

Sin lugar a duda, el principal atractivo de este jardín botánico lo compone la gran colección de palmeras distintas con las que cuenta, con un total de 70 especies, entre 700 y 800 ejemplares. Los más representativos se muestran en la figura 2.

Se podría indicar que el jardín se encuentra en constante evolución y dinamismo, en el que se tiene proyectado contar con otras dos colecciones botánicas bajo techo: la primera de ellas de plantas del género Hoya, cf. Figura 3, más conocida como flor de cera, y la segunda de plantas del género Begonia, cf. Figura 4; ambas de gran interés para los aficionados a la jardinería. Otro atractivo reseñable que presenta dicho jardín está en la introducción de la población de Danaus plexippus, conocida vulgarmente como mariposa 
monarca (figura 5). Se trata de una mariposa de origen tropical que en los últimos años está empezando a colonizar algunas zonas subtropicales de las provincias de Cádiz y Málaga.
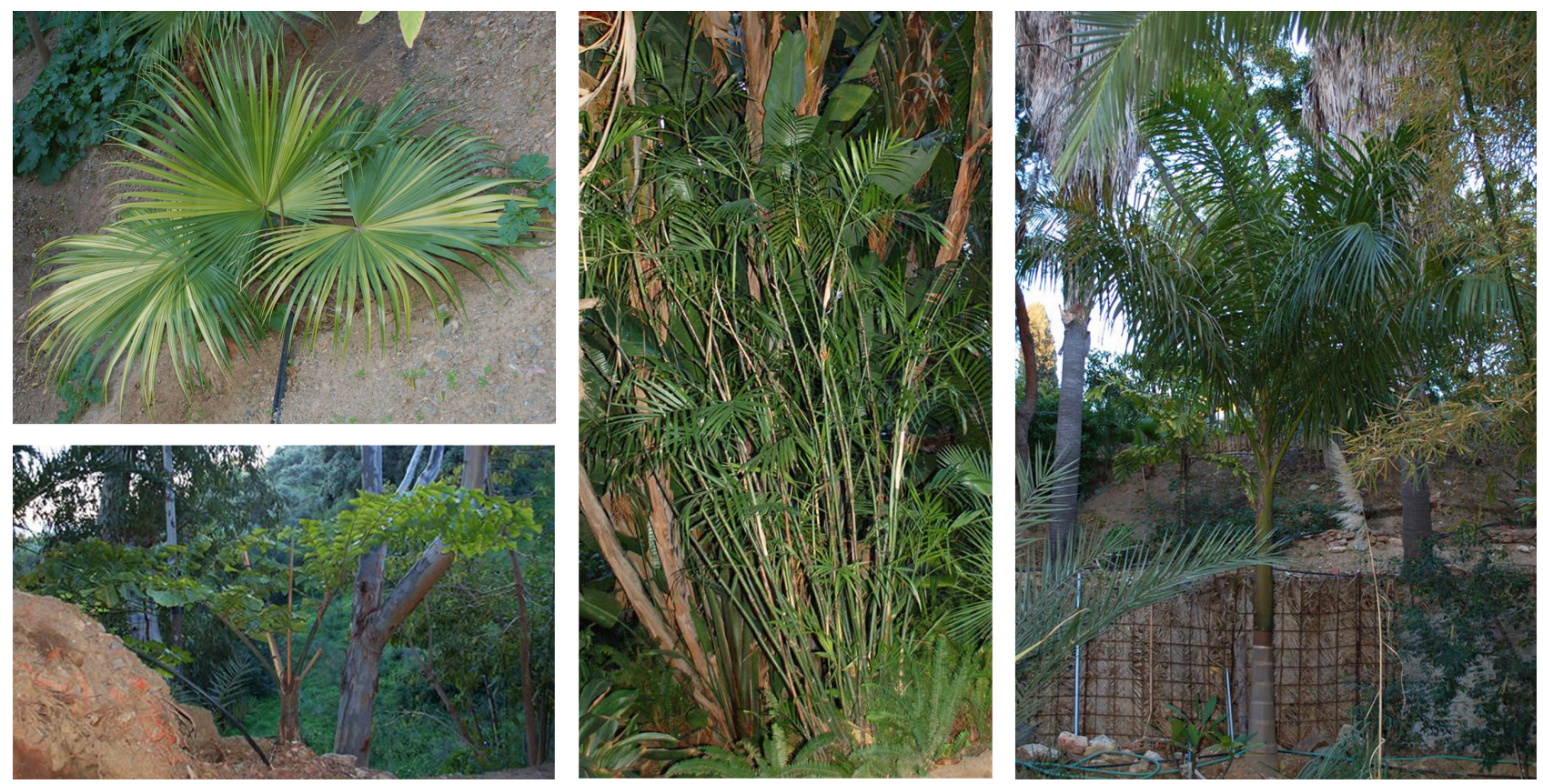

Fig. 2. Ejemplares singulares de palmeras, pertenecientes a la colección botánica del Jardín Botánico "El Cerro".
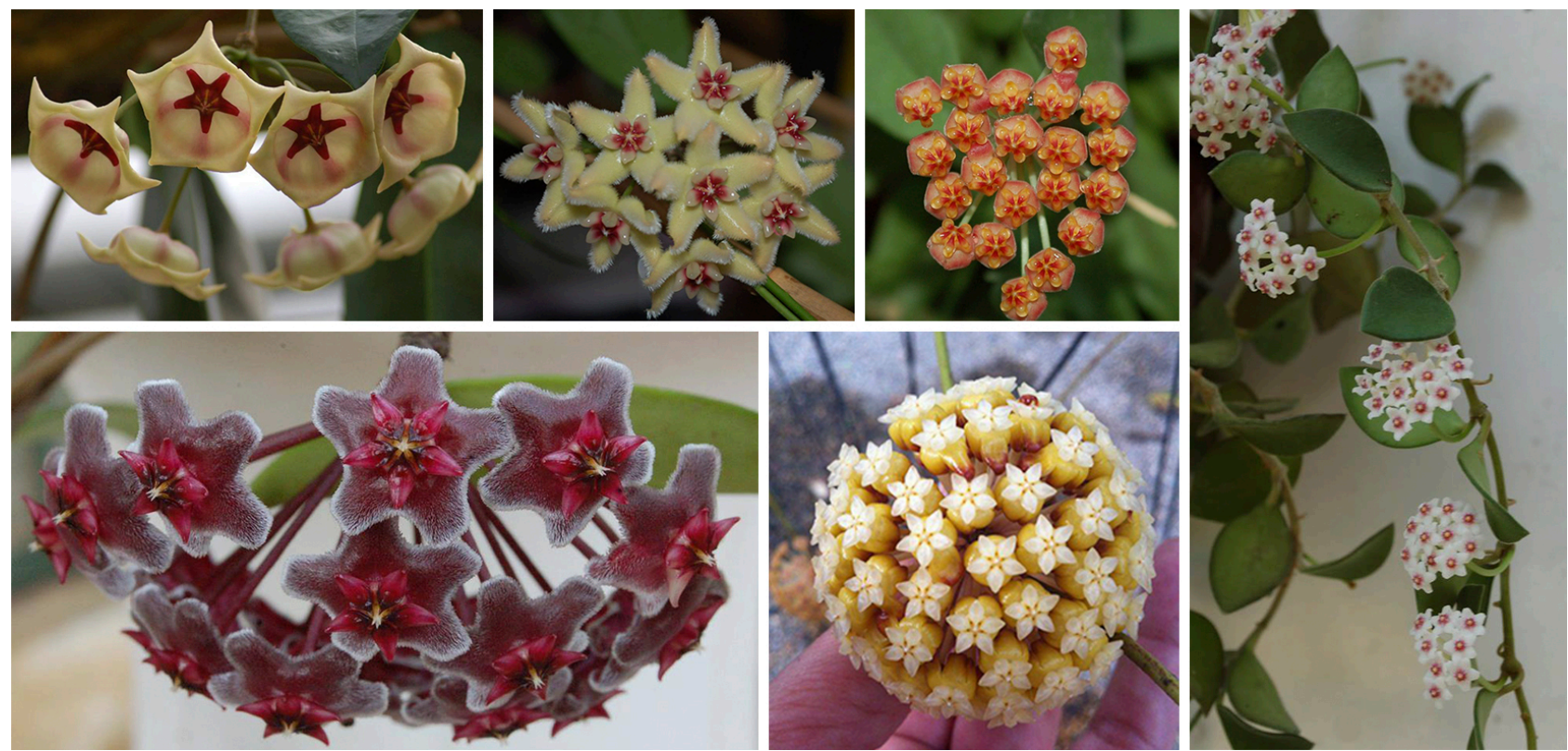

Fig. 3. Especies pertenecientes a la colección botánica del género Hoya del Jardín Botánico "El Cerro”.

Finalmente cabe destacar que el Jardín Botánico "El Cerro" cuenta con zonas diferenciadas que agrupan especies de palmera en su mayoría, aunque existen también congregaciones de otras plantas, principalmente de origen tropical, de distintas áreas geográficas del planeta. 

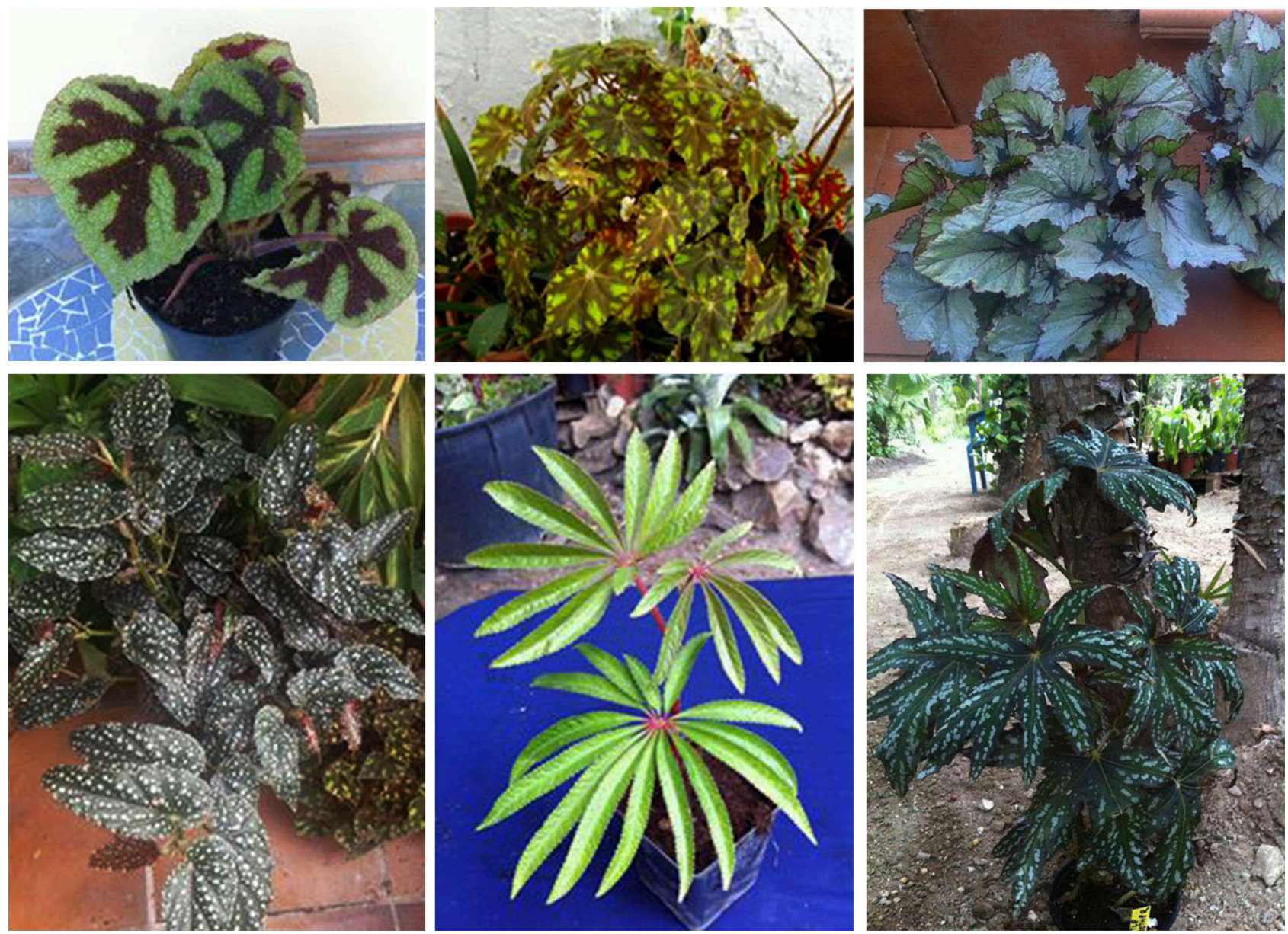

Fig. 4. Especies pertenecientes a la colección botánica del género Begonia, del Jardín Botánico "El Cerro".
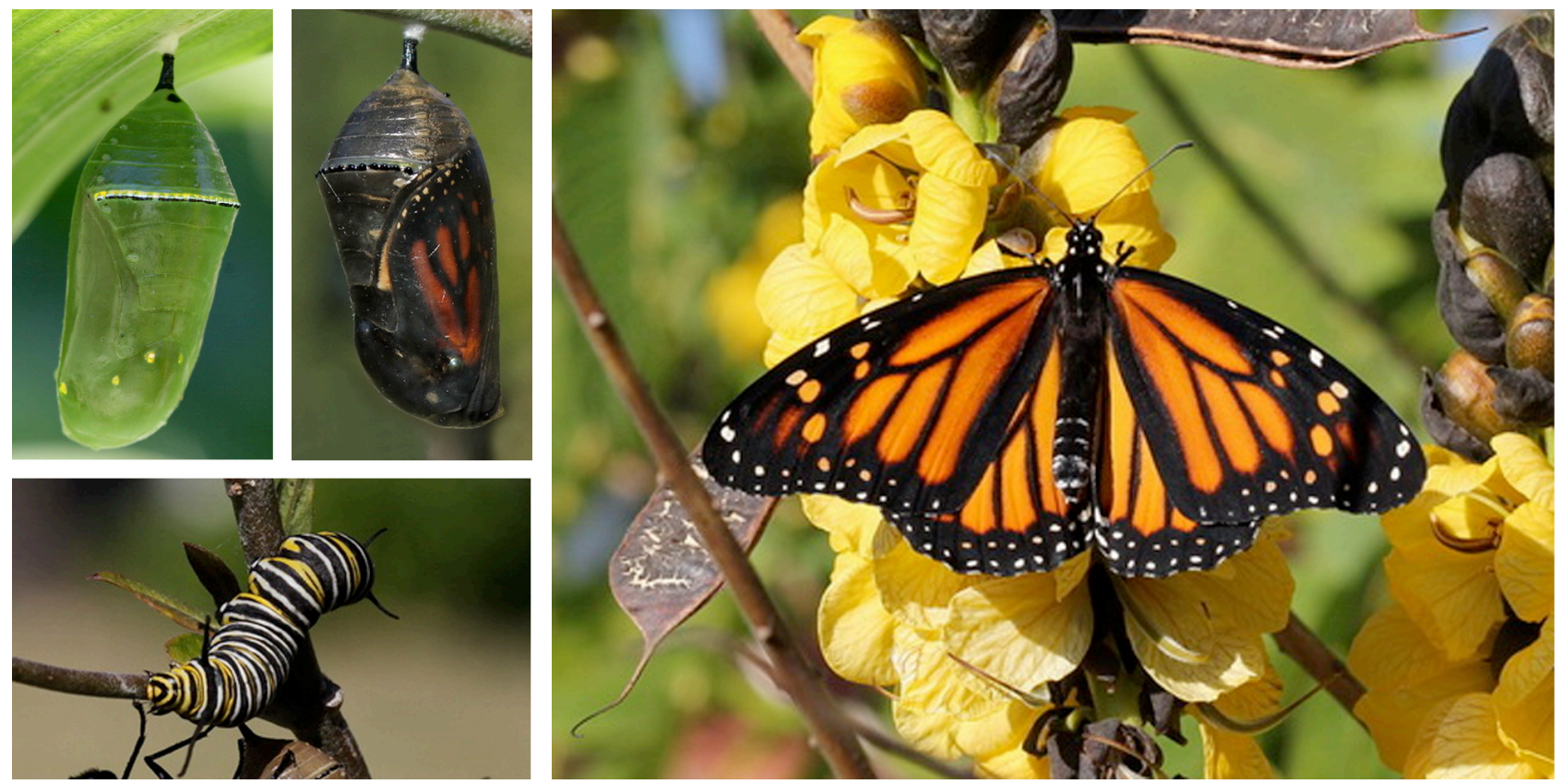

Fig. 5. Estados de la mariposa monarca en su proceso de metamorfosis. Extraídos de <http://www.iberia-natur.com>. 


\section{Mobiliario urbano para jardines: criterios de diseño}

A la hora de realizar un buen diseño, es primordial realizar un buen estudio de los antecedentes de mobiliario urbano en jardines, obteniendo una visión global de lo que existe en el mercado y poder profundizar en los aspectos que se quieren considerar. Partiendo de ahí, se lleva a cabo un análisis que contempla tanto al posible público visitante como a la visión de los propietarios del jardín, llegándose a obtener una serie de ideas posibles. De aquí, se concluye que deben cumplirse una relación de criterios de diseño generales en primera instancia, y otros específicos para cada elemento de diseño en segunda instancia. Tales criterios se reflejan a continuación:

- Búsqueda de la armonía con el entorno.

- Diseños con factores estéticos comunes: con objeto de conservar y realzar la sensación de línea de productos.

- Diseños que sirvan como seña de identidad: se basarán en los principales atractivos del jardín botánico.

- Uso de materiales resistentes al entorno: deberán soportar humedad, lluvia, viento, salinidad de la zona, etc.

- Facilidad de limpieza y mantenimiento: se buscará la simplicidad, superficies lisas, fáciles de desmontar en caso de ser necesario, etc.

- Diseños higiénicos: prestando especial atención a las superficies de contacto directo con el usuario.

- Cumplimiento de los criterios de accesibilidad universal: aspecto muy importante en el campo del diseño industrial en general. Además, los propietarios del jardín botánico están poniendo especial interés a la hora de configurar los accesos, el sendero y servicios prestando atención en hacerlos accesibles a todos los públicos en la medida que sea posible.

En segundo lugar, tras el consiguiente brainstorming se incluyen los criterios de diseño específicos para cada elemento de mobiliario y grafismo, como son los siguientes:

- Se pretende que el banco represente el espíritu principal del Jardín Botánico "El Cerro". De esta forma, se resuelve que su diseño esté basado en la figura de una palma de palmera.

- Se decide emplear una papelera con clasificación de residuos que incluya los tres tipos de residuos considerados como los más imprescindibles, dado el público visitante. Estos tres tipos de residuos son: papel, envases y resto de residuos, y deberán ir representados, con los colores azul para el papel, amarillo para los envases y verde oscuro para el resto de residuos. Esta cualidad vinculada al reciclaje, se usará para darle una dimensión semántica al diseño. Para ello, se busca el paralelismo entre la transformación de residuos para su posterior reciclaje y reutilización y la 
metamorfosis de la mariposa monarca, principal atractivo del jardín, motivo por el cual, se basará el diseño de la papelera en la forma de la crisálida de la mariposa monarca.

- Los criterios de accesibilidad se aplican a la fuente de agua potable que deberá tener doble altura para resultar accesible a todo el público visitante. Aprovechando la doble altura, el diseño se fundamenta en la ramificación de un árbol o en troncos de palmera.

- El isologotipo estará basado fundamentalmente en el principal atractivo del jardín botánico "El Cerro", por lo que deberá incluir una o varias palmas. A ser posible se buscarán diseños sencillos, pero a su vez fácilmente reconocibles como seña de identidad. Independientemente, deberá ser escalable sin dejar de reconocerse con claridad.

- En lo referente a la banderola se prestará especial atención a su legibilidad a una distancia óptima especificada. Se situará junto a la entrada en una zona relativamente alta y visible desde la A7, la Autovía del Mediterráneo, que es la principal arteria de tráfico rodado más cercana al núcleo urbano en que se ubica el jardín. Deberá ser un reclamo publicitario que incluya, a ser posible, los principales atractivos del Jardín Botánico.

\section{Diseño del mobiliario}

\section{Banco "PALMA"}

Como ya se ha mencionado con anterioridad, el diseño del banco, denominado "PALMA" se basa en la propia forma de las palmas de palmera, principal atractivo del Jardín Botánico "El Cerro". Es por ello que dicha pieza se convierte en la más representativa (figura 6), que confiere un valor añadido al jardín y, al mismo tiempo, se convierte en su seña de identidad. Este aspecto semántico, a su vez, da nombre al diseño que puede observarse en las figuras 7 y 8 .

En el análisis estético, cabe destacar el uso de formas orgánicas, como las marcadas por su perfil, que contrastan con la linealidad de las secciones que confieren el aspecto de palma de palmera. Esta forma orgánica, a su vez, aporta al banco un contacto con el usuario más agradable, tanto visual como en lo que a ergonomía se refiere, evitando así el contacto directo con ángulos pronunciados.

En cuanto al color se opta por dejar el color natural del hormigón, que a su vez recuerda al de la piedra natural, como puede apreciarse en las figuras 9 y 10.

El cuerpo del banco se realiza en una sola pieza, unido por una nervadura horizontal a la altura del asiento. Aunque se trate de una sola pieza, las secciones que simulan la palma se diseñan para evitar una posible acumulación de agua de lluvia. Del mismo modo, se le confiere una leve inclinación al asiento que evita que se acumule agua sobre él. Se idea para su fabricación el empleo de hormigón UHPC (Ultra High Performance Concrete). Este hormigón permite secciones más delgadas que los hormigones convencionales, con lo cual se reduce el peso y el consumo de material; otra forma de conseguir estas dos 
características, consiste en ahuecar su parte posterior, hecho que además facilita el montaje y desmontaje si fuera necesario en casos de mantenimiento.

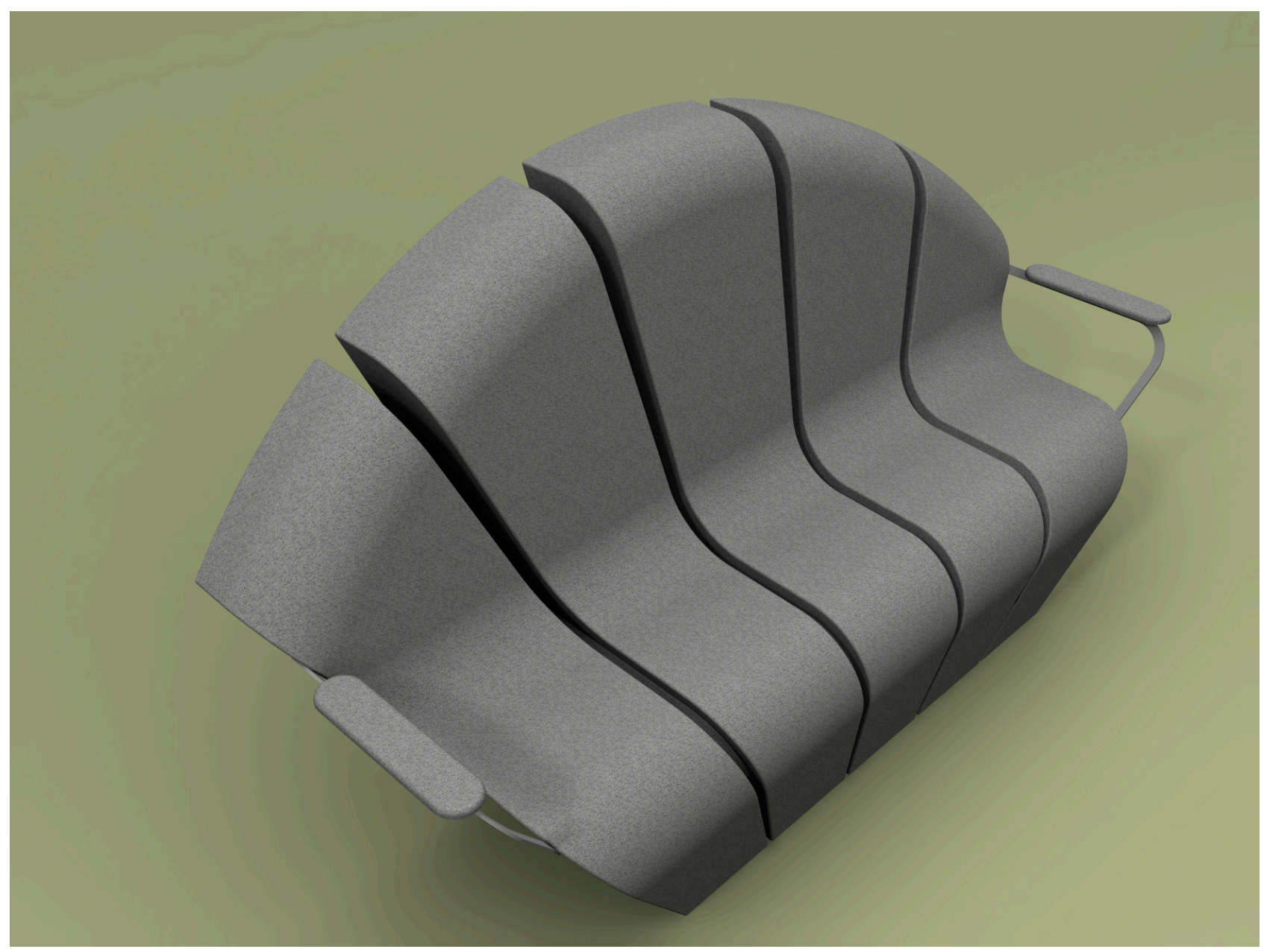

Fig. 6: Vista renderizada en perspectiva del diseño del banco.
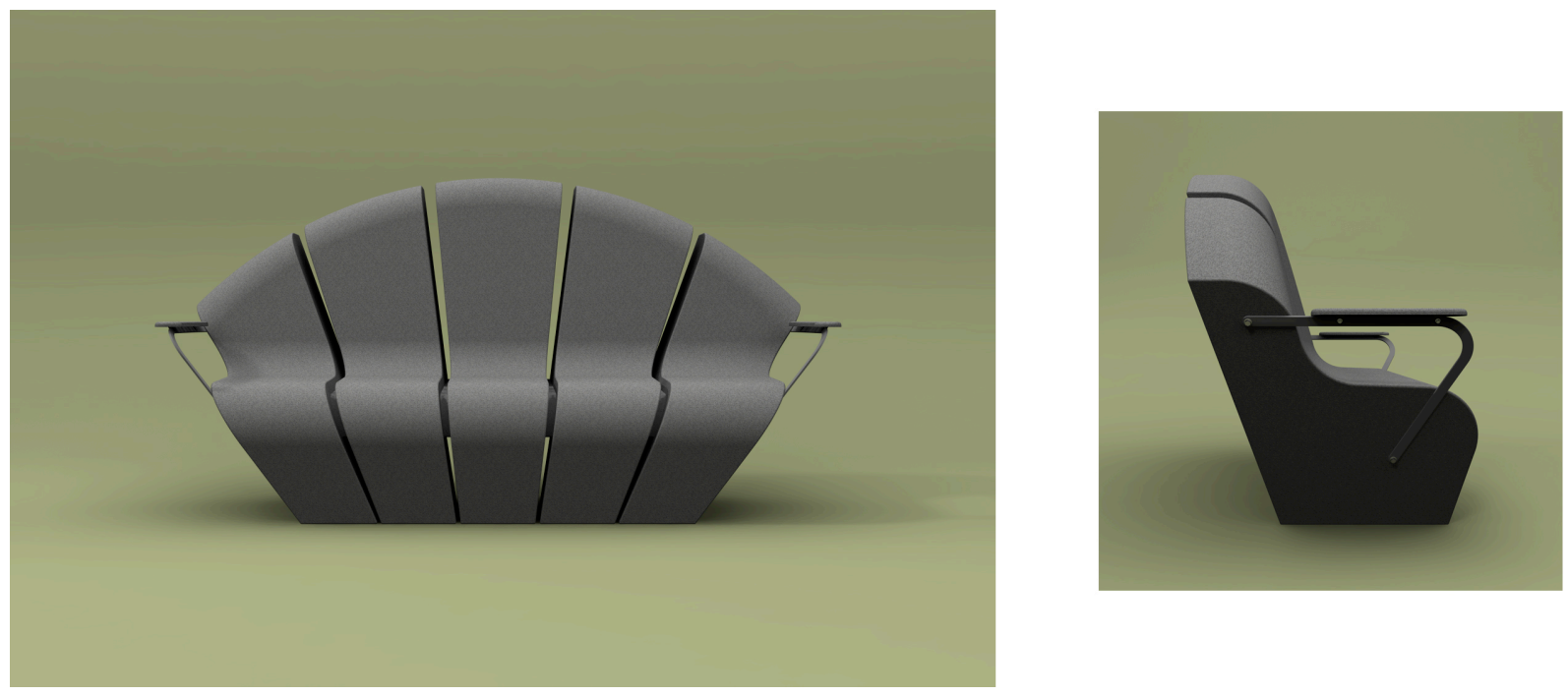

Fig. 7 y 8 . Vista renderizada frontal y de perfil del banco. 
Para hacer cumplimiento de las normas de accesibilidad, el banco "PALMA" dispondrá de un reposabrazos compuesto por una estructura de acero galvanizado, a la que irá fijada la superficie del reposabrazos de contacto directo con el usuario, cuyo material de fabricación será 100\% Poliestireno y Polipropileno reciclado de origen urbano e industrial, simulando en apariencia al hormigón.
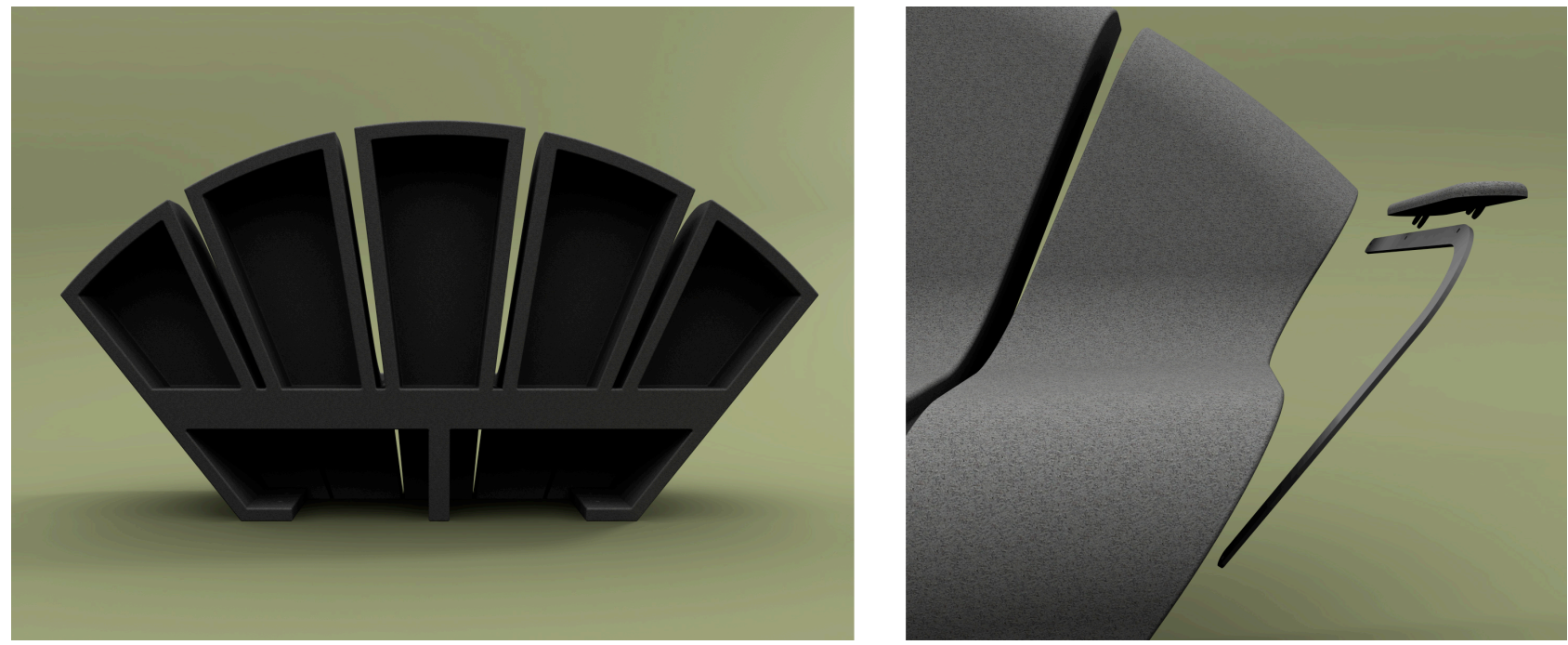

Fig. 9 y 10: Vista renderizada trasera del banco y despiece del reposabrazos.

\section{Papelera de reciclaje "METAMORFOSIS"}

La papelera "METAMORFOSIS" está inspirada en la forma de la crisálida de la mariposa monarca, como metáfora visual que relaciona la transformación de los residuos en material para un segundo uso y la metamorfosis de la mariposa. Con tal propósito, se ha configurado de forma que quede suspendida, a través de un sistema de sujeción consistente en un pie arqueado haciendo alusión a las ramas de las que cuelgan las crisálidas de la mariposa monarca, cf. Figura 11 y 12.

Dispone de tres separadores de residuos: para papel, en color azul, para envases, en color amarillo y para el resto de residuos, en un tono verde oscuro, cf. Figura 13; éstos se han considerado los tres tipos de residuos principales teniendo en cuenta las necesidades y posibles hábitos del público visitante. Se descarta un cuarto espacio separador para vidrio, puesto que hoy en día no es tan común el uso de este tipo de envases para las bebidas. Como puede observarse en las figuras 13 y 14 , el cuerpo de la papelera lleva tres calados frente a cada separador entre otros motivos, para dar una apariencia más liviana al volumen y aportar naturalidad, rompiendo con la sensación artificial que pueda ocasionar la geometría de revolución. Por otro lado, pretende recordar a la configuración de la crisálida de la mariposa monarca que cuando va madurando va oscureciendo pero siempre dejando zonas translúcidas que dejan ver en su interior las alas de la mariposa; de igual forma, la papelera "METAMORFOSIS" deja ver su interior, pudiendo mostrar así las bolsas de distintos colores, correspondientes a cada tipo de residuo.

En la parte inferior de la cubeta, se prevén tres orificios de desagüe para evitar que quede agua almacenada en su interior. Como se puede apreciar, la cubeta es una superficie de revolución, con una tapa 
que da acceso a tres tipos de residuos diferentes, dividiendo la circunferencia que la forma en tres zonas de $120^{\circ}$ cada una con su correspondiente orificio para depositar los residuos.
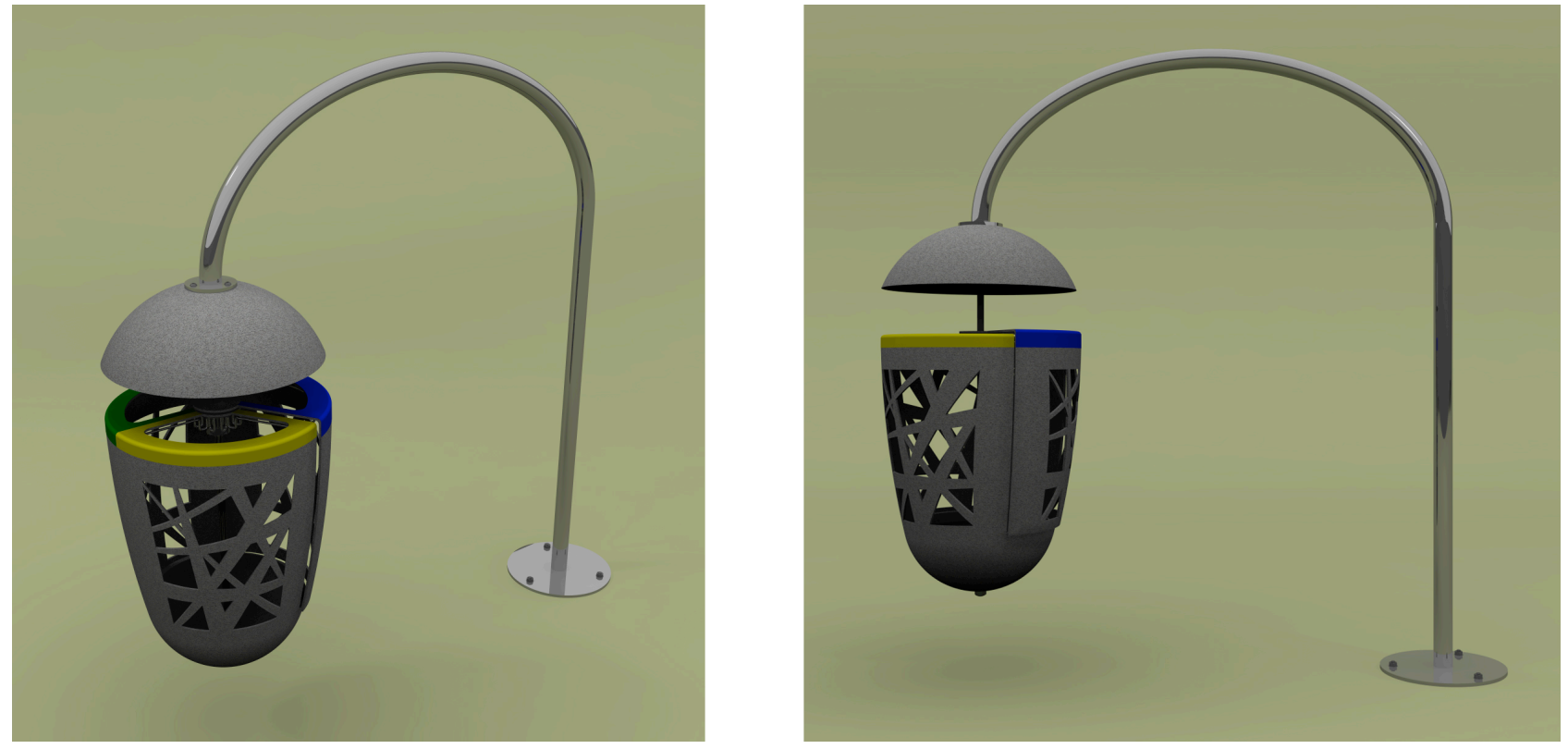

Fig. 11 y 12: Vista renderizada en perspectiva del diseño de la papelera y vista de perfil.
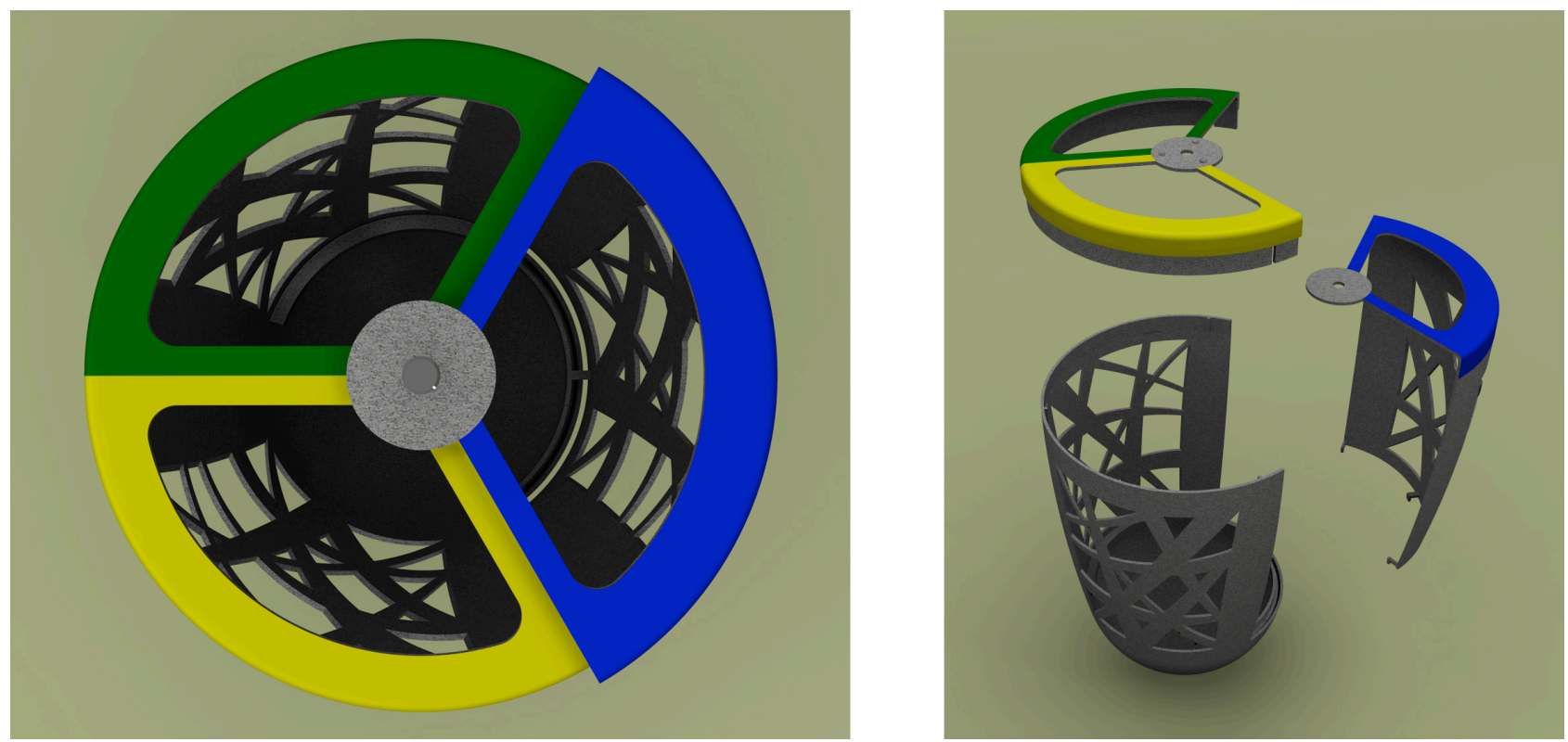

Fig. 13 y 14: Vista de detalle de los separadores de residuos y despiece de la cubeta.

Su sistema de vaciado, cf. Figura 15, consiste en una puerta giratoria, que se desliza hacia la derecha a través de railes hasta su apertura total. Una vez abierta, el operario extraerá la bolsa de residuos que primero encuentra, que es la de papel, y a continuación irá girando el aro que porta las bolsas para acceder a las bolsas de los demás separadores. 


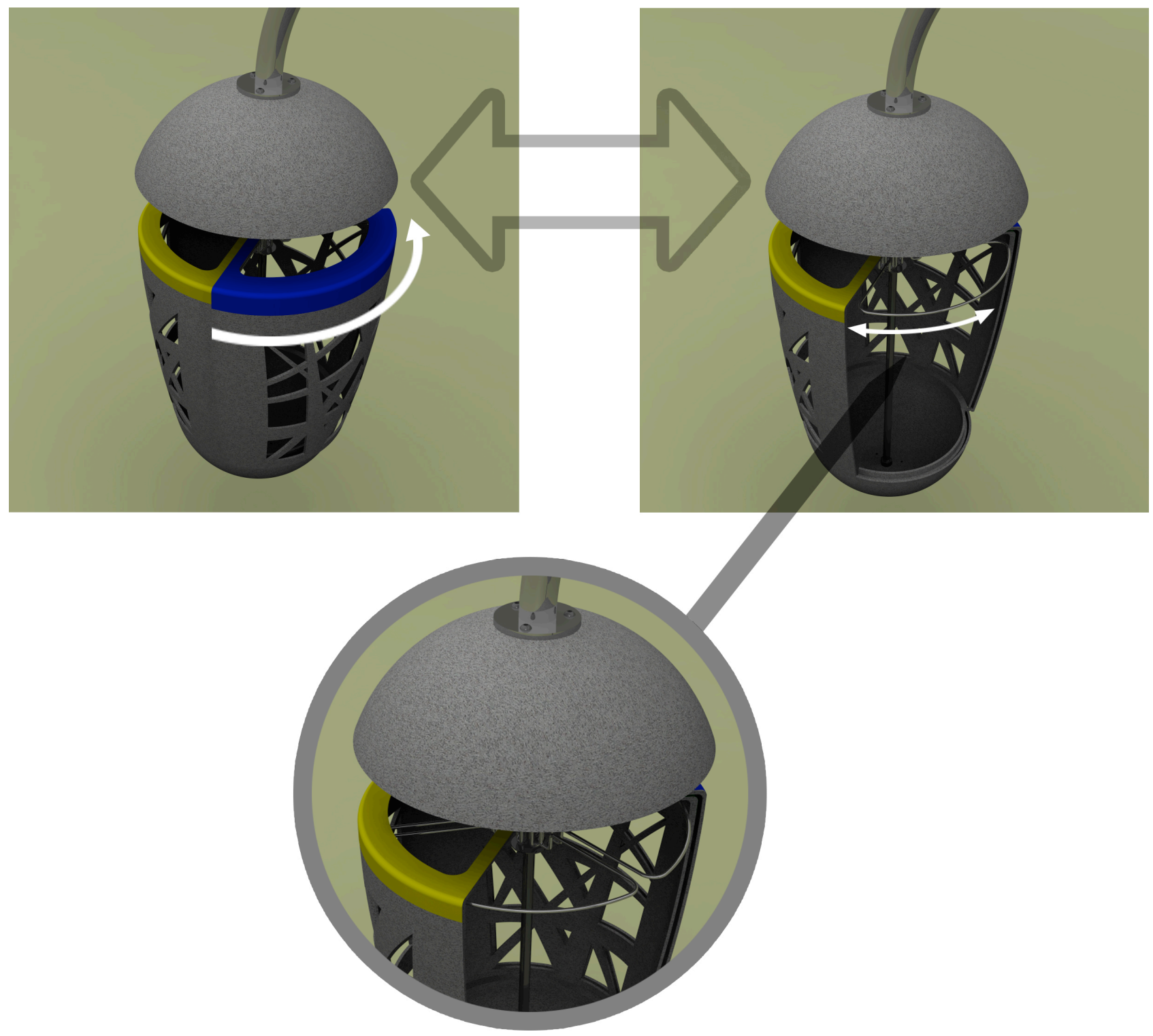

Fig. 15: Sistema de vaciado de la papelera de reciclaje.

En el interior de la cubeta, el sistema está diseñado de tal forma que se reduzcan los puntos de contacto entre el aro que porta las bolsas, el eje de rotación, la pletina de apoyo que va soldada al propio eje y otra pletina de deslizamiento que se sitúa por encima del aro para evitar, en todo caso, el desgaste de la tapa. La figura 16 ilustra tal mecanismo.

El conjunto exterior que forman la cubeta y la tapa protectora de la lluvia, se fabrican en el mismo material que la superficie del reposabrazos del banco; mientras, el mecanismo interno y el pie arqueado, son fabricados en acero ANSI 316. Este acero tiene la particularidad de ser altamente resistente a ambientes marinos. 


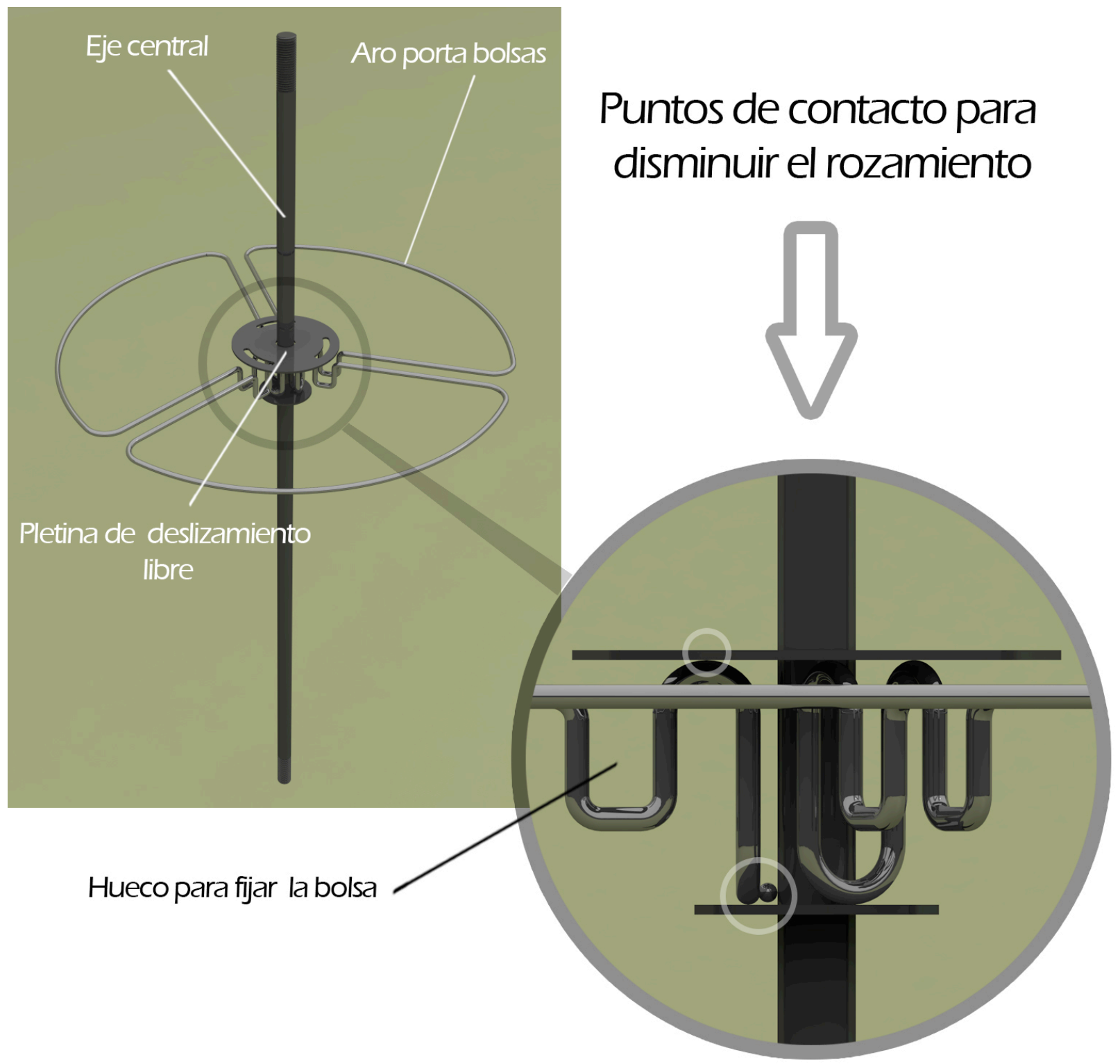

Fig. 16: Detalle del subconjunto de deslizamiento eje, aro y pletina.

\section{Fuente "RAMA"}

La fuente "RAMA" se inspira, como su nombre indica, en la ramificación más básica de los árboles, aprovechando así su disposición de grifos a doble altura para hacerla accesible a todo el público visitante, incluyendo a personas usuarias de sillas de ruedas, niños, y adultos de distintas alturas y edades, como indica la figura 17. En el alzado de la figura 18, se puede apreciar que se dispone un espacio libre bajo cada plato, diseñado para facilitar el acercamiento a personas usuarias de silla de ruedas.

Su configuración corresponde a la de una fuente de plato a doble altura con sistema de desagüe exterior en cascada, para evitar atascos en el interior del cuerpo de la fuente. Al dejar vista la caída del agua se aporta un valor añadido estético, a la vez que se destaca un elemento tan importante en la naturaleza. 


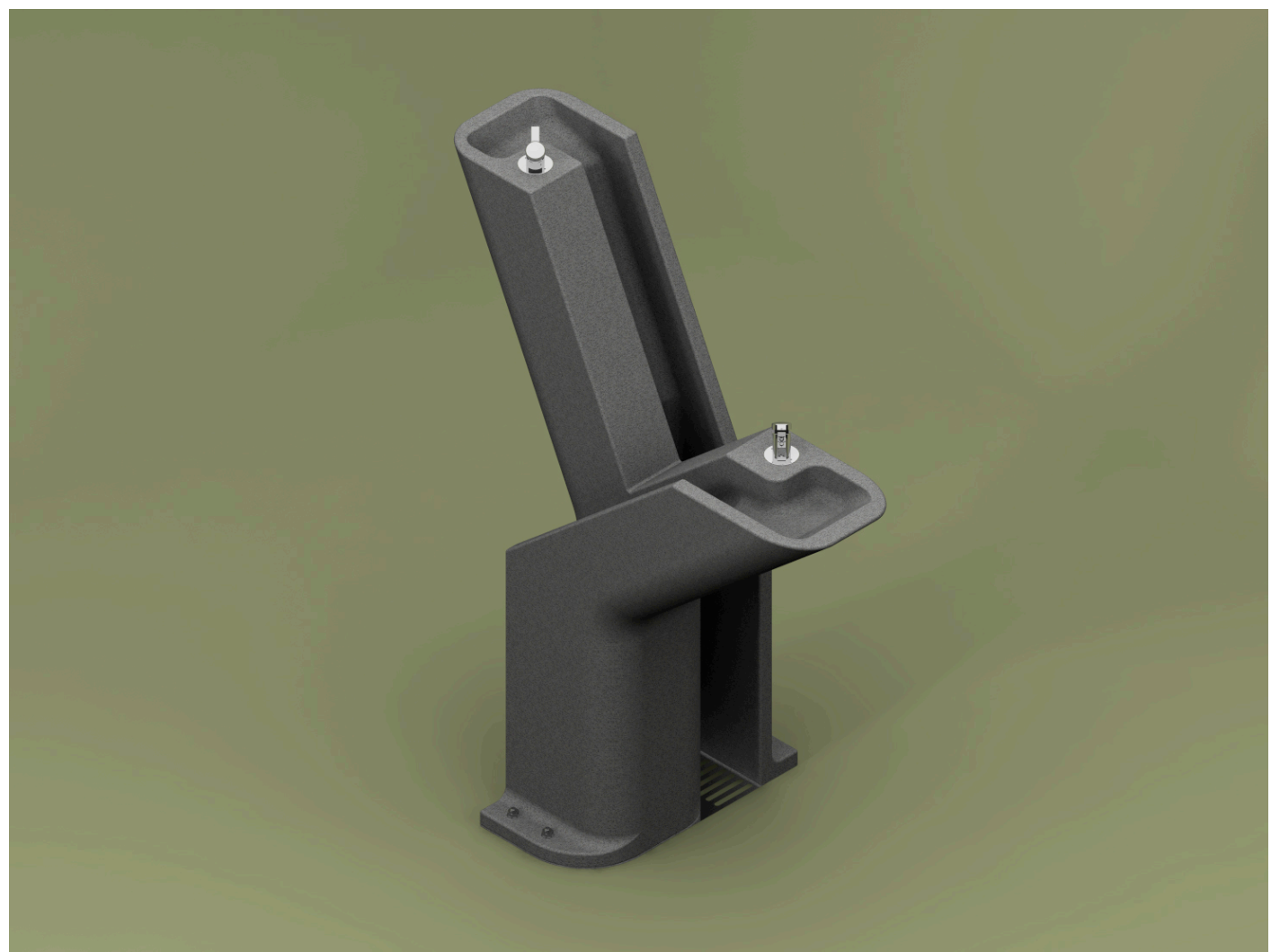

Fig. 17: Vista renderizada en perspectiva de la fuente.

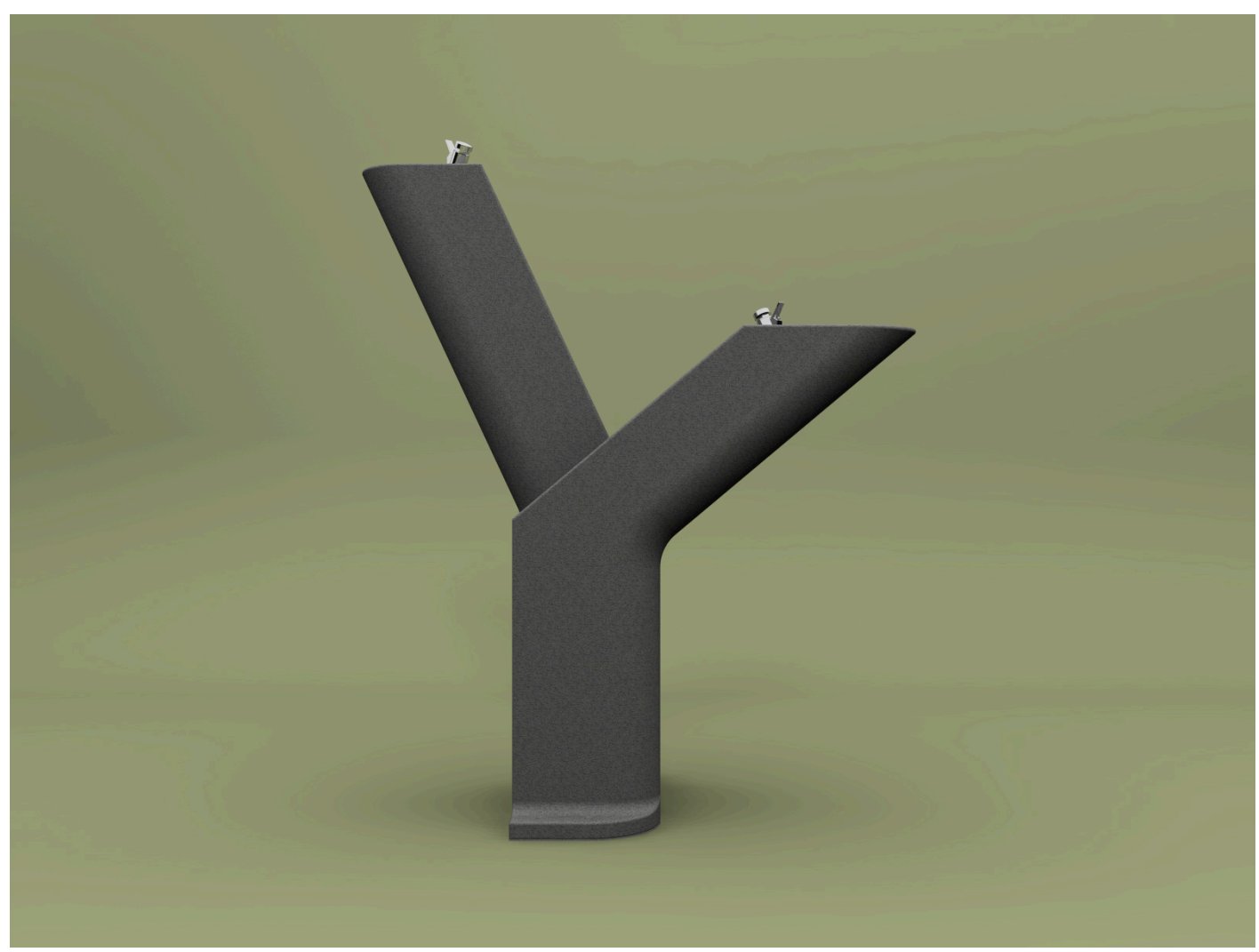

Fig. 18: Vista renderizada del alzado de la fuente. 
Como se puede observar, el agua cae hacia el lado opuesto de la persona que se encuentra bebiendo en ese plato, con lo que se reducen las posibilidades de salpicaduras. Asimismo, para evitar salpicaduras a otro usuario que pueda estar usando el otro plato, las paredes del canal de desagüe han sido diseñadas de tal forma que el agua se desliza a través de ellas en forma de cascada, como muestra la figura 19.

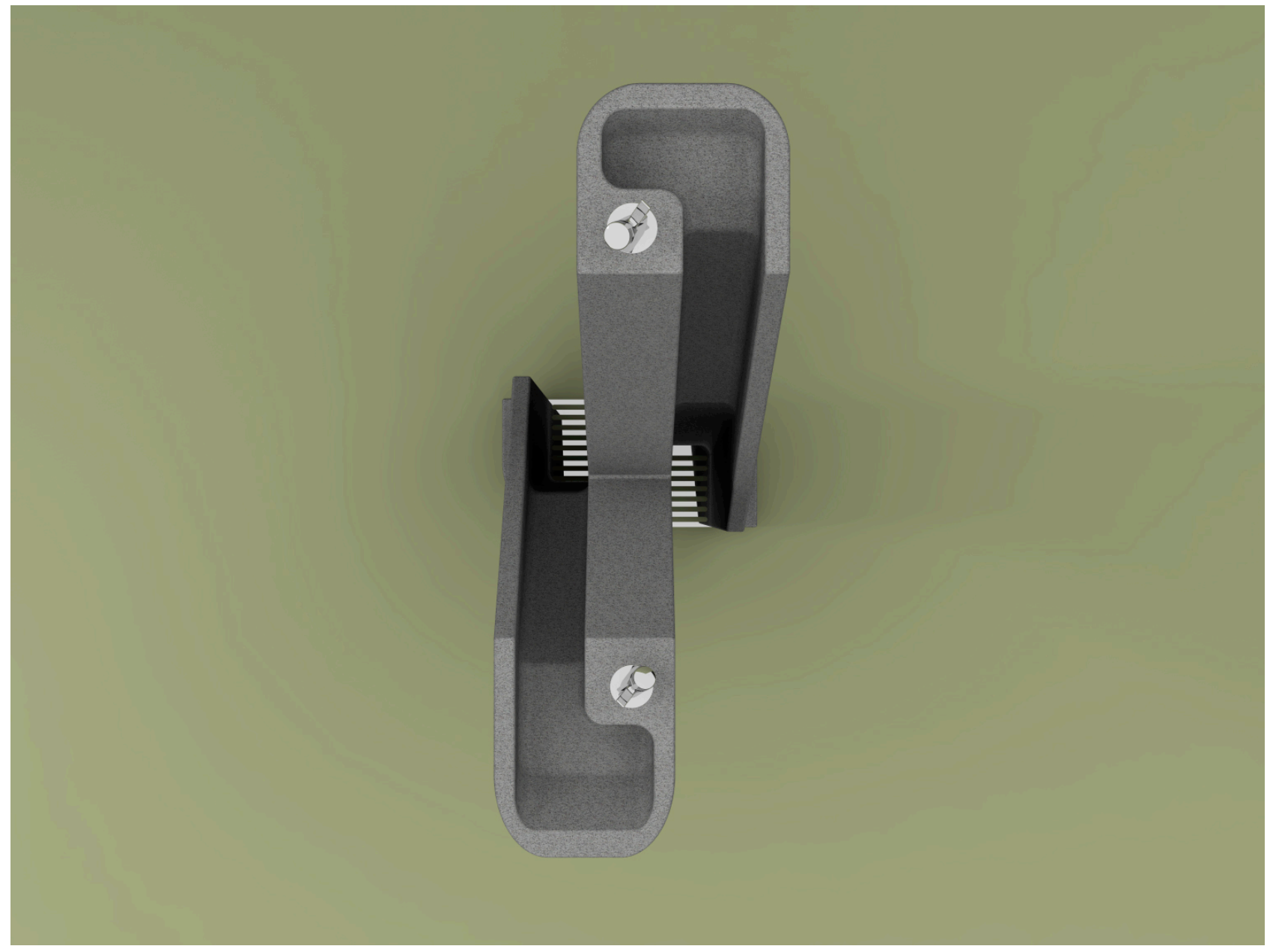

Fig. 19: Vista renderizada superior de la fuente .

La grifería usada para esta fuente de agua potable, es el modelo AQBM300 de la marca Franke. Se trata de un grifo de latón, de accionamiento manual temporizado y con tornillo para regulación de flujo.

El cuerpo de la fuente se proyecta para su fabricación en el mismo material que el cuerpo del banco.

\section{Accesibilidad}

Para diseñar los diferentes elementos de mobiliario urbano que se incluirán en el jardín se han seguido una serie de normas de accesibilidad, que se recogen a nivel estatal en el Real Decreto 505/2007, en la Orden VIV/561/2010 y, a nivel autonómico, en el Decreto Andaluz de Accesibilidad de abril de 2012. Cabe destacar que la normativa andaluza cumple con todas las directrices de la norma estatal, a excepción de algunos 
casos en los que es más restrictiva en cuanto a los rangos máximos y mínimos de sus medidas aceptadas. Éste es el caso de la medida máxima del respaldo, marcada en rojo, únicamente recogida en la normativa andaluza puesto que la estatal solo la limita a un valor mínimo. Esto influye, por ejemplo, en el diseño del banco, pues ese pequeño rango marcado por la normativa andaluza dificultaba el trazado de la forma de palma de palmera por lo que, siguiendo la norma estatal que permite evitar alguna de las medidas por cuestiones artísticas, se traza el respaldo respetando únicamente su medida mínima.

En este apartado se recoge una breve sinopsis de las principales medidas que afectan al diseño del mobiliario urbano de este jardín. Además, se incluyen algunas recomendaciones no incluidas en las normas para que los diseños realizados aseguren la accesibilidad universal en este lugar.

En cuanto a la papelera, el rango de medida que limita la altura de la boca marcada en verde, es la única norma referente en exclusiva a su diseño, aunque se han de respetar el resto de normas concernientes a su posterior situación en el terreno. En el caso de la fuente de agua potable, las normas de accesibilidad recogen dos recomendaciones, en concreto, las marcadas en naranja en la figura 20. Estas recomendaciones son importantes para la accesibilidad universal, puesto que no sólo se debe prestar atención al plato bajo o adaptado a personas en silla de ruedas y niños, sino también a su plato alto, pues éste deberá tener unas medidas adecuadas para que al beber en él una persona de gran altura no tenga que agacharse en exceso pudiendo llegar a dañar su espalda.
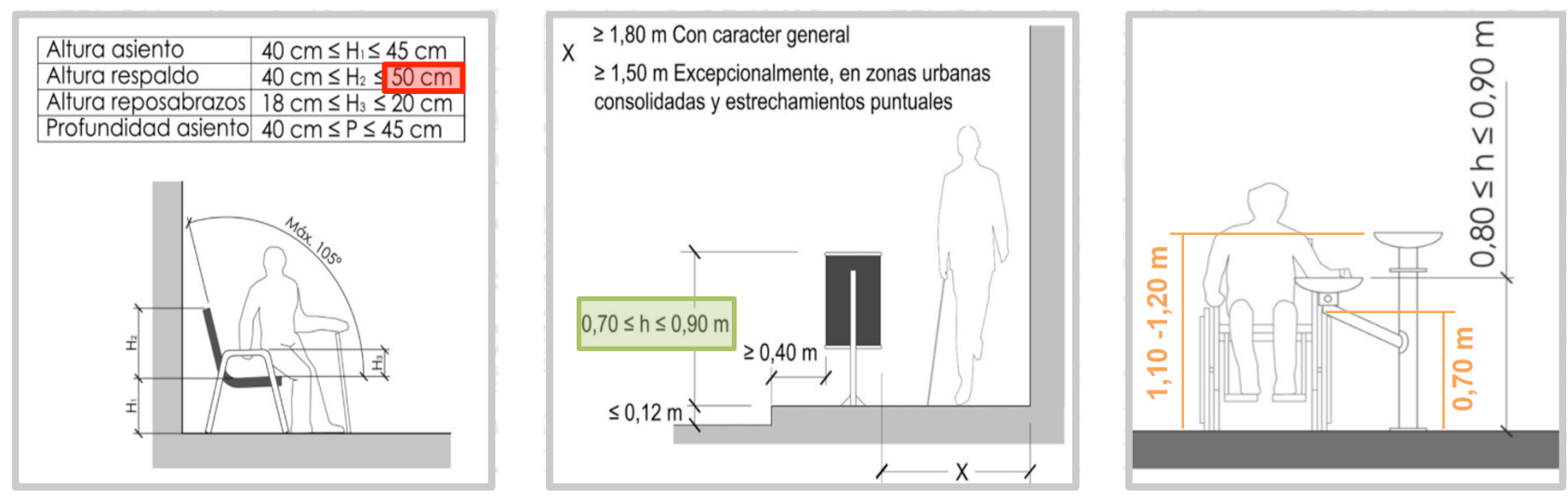

Fig. 20. Ilustraciones extraídas del Documento Técnico sobre el Decreto Andaluz de Accesibilidad, de abril de 2012, en la que se muestran las medidas mínimas y máximas para la consecución del diseño accesible para bancos, papeleras y fuentes de agua potable. Han sido levemente modificadas, con añadidos, para la comprensión de algunos detalles en ésta explicación.

Además de lo anteriormente descrito, se siguen recomendaciones recogidas por parte de asociaciones de personas usuarias de sillas de ruedas. Una de estas recomendaciones indica que la fuente de agua potable debe tener un hueco bajo el plato adaptado, de tal forma que facilite al usuario el acercamiento frontal al plato, sin adquirir una postura complicada. 


\section{Conclusiones}

Las zonas verdes contribuyen a la recreación y disfrute de los ciudadanos, además de representar un legado ecológico y sostenible para las generaciones actuales y venideras. Por todos es conocida la defensa de los espacios públicos a través de distintas ordenanzas municipales y asociaciones.

El diseño industrial está íntimamente relacionado con el diseño de los elementos que caracterizan el mobiliario urbano en los jardines, aportándole estética a la vez que funcionalidad a los mismos. Un buen estudio de los criterios de accesibilidad es fundamental para la satisfacción del público que hace uso de los servicios.

Finalmente indicar que los principales atractivos del Jardín Botánico de "El Cerro" son las palmeras y la mariposa monarca, por lo que como se ha podido comprobar son una seña de identidad en el diseño de dicho mobiliario, consiguiendo una excelente armonía con el entorno.

\section{REFERENCIAS}

BERMÚDEZ LÓPEZ, J. La Alhambra y el Generalife, Guía Oficial. TF Editores, 2009.

BULUT, Z., YILMAZ, H. Determination of landscape beauties through visual quality assessment method: A case study for Kemaliye (Erzincan/Turkey) (2008) Environmental Monitoring and Assessment, 141 (1-3), pp. 121-129.

CARPIO PONCE, A. I., CONDE OLIVA, J., SÁNCHEZ GARCÍA, O., VÉLEZ MATEO, C. Documento Técnico sobre el Decreto Andaluz de Accesibilidad, Dirección General de Personas con Discapacidad, Junta de Andalucía, 2012 [en línea] http://www.juntadeandalucia.es/export/drupaljda/Documento Tecnico Accesibilidad Abril 2012.pdf (15.10.2016)

DANIEL, T.C. Measuring the quality of the natural environment: A psychophysical approach (1990) American Psychologist, 45 (5), pp. 633-637.

DANIEL, T.C. Whither scenic beauty? Visual landscape quality assessment in the 21 st century (2001) Landscape and Urban Planning, 54 (1-4), pp. 267-281.

FERNÁNDEZ GARCÍA, R. Historia del Jardín Sevillano: Recopilación y edición crítica de fuentes, Tesis doctoral defendida en el Departamento de Expresión Gráfica Arquitectónica. Universidad de Sevilla, 1995

Gini, A. Concrete Jungle in Xilitla (2003) Travel and Leisure [en línea] http://www.travelandleisure.com/articles/concretejungle

LARRODERA LÓPEZ, E. Anotaciones sobre cuarenta años de planeamiento urbanístico en España, Complementos al Curso sobre Figuras del Planeamiento y su Gestión. Comisión de Urbanismo y Vivienda COAM, Madrid, 1982.

MAHDIEH, A., MUSTAFA KAMAL, M.S., SUHARDI, M., SEYED, R.D. Determining the visual preference of urban landscapes (2011) Scientific Research and Essays, 6(9), pp. 1991-1997.

ÖZGÜNER, H. Cultural differences in attitudes towards urban parks and green spaces (2011) Landscape Research, 36 (5), pp. 599-620.

POLAT, A.T., AKAU, A. Relationships between the visual preferences os urban recretation area users and various landscape design elements (2015) Urban Forestry and Urban Greening, 14 (3), pp. 573-582.

TROITIÑO VINUESA, M.A. Las áreas urbanas en Atlas Estadístico de las Áreas Urbanas de España 2006, Madrid, Ministerio de la Vivienda, pp. 27-51. 